\title{
Pesquisa-intervenção sobre violências em escolas
}

\author{
Irme Salete Bonamigo \\ Universidade Comunitária da Região de Chapecó - SC \\ Celso Francisco Tondin \\ Universidade Comunitária da Região de Chapecó - SC \\ Ana Paula Risson \\ Universidade Comunitária da Região de Chapecó - SC \\ Alana Lazaretti Solvalagem \\ Universidade Comunitária da Região de Chapecó - SC
}

\begin{abstract}
Resumo
Este artigo discute o tema violências nas escolas a partir da descrição e análise de um processo de restituição de pesquisa sobre práticas violentas nas escolas envolvidas, por meio da pesquisa-intervenção. Ao mesmo tempo em que se fez a restituição, produziram-se novas informações. A pesquisa abrangeu doze escolas públicas estaduais e 408 participantes: 221 alunos, 105 professores, 63 pais, oito coordenadores pedagógicos e onze diretores. A pesquisa-intervenção tornou o processo de restituição de conhecimento um laboratório de experimentação coletiva. Compreende-se que as práticas violentas em escolas precisam ser tomadas como potência, ou seja, como conflitos que expressam forças que estão em jogo no espaço institucional e que questionam o modo hegemônico da organização escolar, ritualizado e enrijecido, e o funcionamento social, individualista e competitivo. A proposta é sair do território do indivíduo para pensar o fenômeno como expressão social, política, econômica e cultural.
\end{abstract}

Palavras-chave: Violência; Psicologia e Educação; políticas públicas.

\section{Intervention-research on violence in schools}

\begin{abstract}
In this article we discuss the issue of violence in schools, from the description and analysis of a process of restitution of research on violent practices in the involved schools. While the restitution was made, it was produced new information. The survey covered 12 public schools and 408 participants: 221 students, 105 teachers, 63 parents, 8 coordinators and 11 directors. The intervention-research became the knowledge restitution process a laboratory for collective experimentation. It is understood that the violent practices in schools need to be taken as power, in other words, as conflicts that express forces that are at play in the space and that challenge the institutional hegemonic mode of the school organization ritualized and stiff, and the social functioning individualistic and competitive. The proposal is to leave the individual territory to think the phenomenon such as an expression of social, political, economic and cultural.
\end{abstract}

Keywords: Violence; Psychology and Education; public policies.

\section{Investigación-intervención sobre violencias en escuelas}

\section{Resumen}

Este artículo discute el tema violencias en las escuelas a partir de la descripción y análisis de un proceso de restitución de investigación sobre prácticas violentas en las escuelas arrolladas, por intermedio de la investigación-intervención. A la vez en que se hace la restitución, se produjeron nuevas informaciones. La investigación abarcó doce escuelas públicas estaduales y 408 participantes: 221 alumnos, 105 profesores, 63 padres, ocho coordinadores pedagógicos y once directores. La investigación-intervención volvió el proceso de restitución de conocimiento un laboratorio de experimentación colectiva. Se comprende que las prácticas violentas en escuelas necesitan ser tomadas como potencia, es decir, como conflictos que expresan fuerzas que están en juego en el espacio institucional y que cuestionan el modo hegemónico de la organización escolar, ritualidad y enrojeciendo, y el funcionamiento social, individualista y competitivo. La propuesta es salir del territorio del individuo para pensar el fenómeno como expresión social, política, económica y cultural.

Palabras-clave: Violencia; Psicología y Educación; políticas públicas. 


\section{Introdução}

A categoria violência comporta múltiplos significados na contemporaneidade, por isso a utilizamos no plural (violências): para dar visibilidade às diferentes situações e aos múltiplos eventos com as motivações e contextualizações várias que a palavra comporta. Para discutir sobre violências no cenário da escola com o cuidado de não generalizar nem naturalizar práticas, as pesquisas são um importante dispositivo, pois permitem abranger as singularidades presentes nas realidades das escolas, cidades e regiões.

Em Chapecó (SC) não havia informações sistematizadas sobre violências em escolas, apenas divulgações de ocorrências pela mídia e demandas pelo trabalho do psicólogo para discutir esse tema. Tendo em vista esse cenário, em 2009 foi feita uma pesquisa exploratória ${ }^{1}$, a qual mapeou práticas violentas em treze escolas públicas estaduais de Chapecó (SC), por meio de questionários, com 963 participantes (estudantes, professores e familiares). Essa pesquisa possibilitou identificar as práticas violentas mais presentes nas escolas na concepção dos participantes, sendo distinguidos três tipos de práticas violentas: a) violências na escola: agressão verbal entre alunos, agressões físicas leves entre alunos e ameaças entre alunos; b) violências contra a escola: vandalismo e furto de materiais e equipamentos da escola, agressões verbais e ameaças de alunos contra professores; c) violências da escola: agressões verbais e ameaças de professores contra alunos. Com essa classificação foi analisado o papel da escola com relação às violências com base em Charlot (2002), para quem, diante da ocorrência de "violência na escola" esta estaria mais impotente e dependeria de dispositivos outros vinculados à segurança pública e outras organizações sociais; já diante da "violência contra a escola" e "da escola", haveria margem para ações relacionadas à dinâmica das relações escolares e à organização escolar.

A partir dos resultados dessa pesquisa quantitativo-exploratória², decidiu-se realizar outras pesquisas qualitativas complementares. A primeira delas é a presente investigação, que teve como foco a restituição às escolas das informações produzidas, e como objetivo, a produção de novas informações sobre violências em escolas. $O$ método da pesquisa-intervenção permitiu a realização desta nova pesquisa, pois ao mesmo tempo em que se fez a restituição, registraram-se e analisaram-se as práticas e reflexões que constituíram todo o processo.

Concebe-se a restituição, conforme Lourau (1993, p. 56), como uma "atividade intrínseca à pesquisa" que se constitui em devolver às pessoas participantes e às que vi-

\footnotetext{
1 A pesquisa denomina-se "Mapeamento de práticas violentas em escolas públicas de Chapecó (SC) como contribuição para a formação e o exercício profissional do psicólogo", foi coordenada pelos professores Irme Salete Bonamigo e Celso Francisco Tondin, com a participação dos seguintes acadêmicos do Curso de Psicologia: Francieli Bortolossi, Daniela Fernanda Schott, Ana Paula Risson, Karina Paula Seraglio, Juciane Lopes e Maxemino Luiz Martinelli. A versão completa da pesquisa foi publicada por Bonamigo e cols. (2012).
}

2 Além dos autores, a estudante do Curso de Psicologia Giovane Biazzi também participou de parte da realização da pesquisa. vem e produzem as práticas pesquisadas o saber científico que conseguiram construir.

Se a população estudada recebe esta restituição, pode se apropriar de uma parte do status do pesquisador e tornar-se uma espécie de "pesquisador-coletivo", sem a necessidade de diplomas ou anos de estudos superiores, e produzir novas restituições [...] Isto seria, efetivamente, a socialização da pesquisa (Lourau, 1993, p. 56).

Lourau (1993, p. 55) destaca, ainda, a importância de que o processo envolva “(...) uma restituição pessoal, implicada e posta, dentro da pesquisa, como um procedimento real e necessário do ato de pesquisar (intervir)".

O processo de restituição da pesquisa, que fez parte do processo da nova pesquisa demandou o planejamento, o desenvolvimento, o registro e a análise das novas informações produzidas, por meio de sua apresentação e discussão dos resultados nas escolas que participaram do mapeamento, para reflexão sobre as informações produzidas, a discussão de concepções e o delineamento de caminhos para o enfrentamento das violências presentes no cotidiano da escola.

Desse modo, a pesquisa teve como objetivo geral acompanhar e analisar a restituição da pesquisa sobre mapeamento de violências em escolas públicas de Chapecó às escolas e comunidades envolvidas. Os objetivos específicos foram: 1- descrever os procedimentos dos pesquisadores na condução da restituição da pesquisa; 2- identificar a participação dos diferentes atores (direção, pais, estudantes, professores e funcionários) no processo de restituição; 3- compreender, com base nos resultados, qual foi, para os participantes, a significação ou ressignificação da categoria violência; 4- descrever as informações, complementares ao mapeamento que emergiram no processo de restituição; 5- identificar as soluções apontadas pelos diferentes atores para as situações de violência mapeadas pela pesquisa.

O objetivo do presente artigo é relatar e discutir o processo de pesquisa possibilitado pela restituição, analisando, em especial, se o mapeamento de violências pode ser utilizado como um dispositivo de intervenção do psicólogo na escola, para mobilizar os diferentes atores e contribuir com a reflexão sobre questões que atravessam a comunidade escolar e analisar se a pesquisa-intervenção pode ser uma ferramenta teórico-metodológica para a realização desse processo de restituição e produção de conhecimento.

\section{Método}

\subsection{Fundamentos teórico-metodológicos}

Para a realização da pesquisa foram utilizados os referenciais da pesquisa-intervenção, que busca, segundo Rocha (2006), dar visibilidade às ações, às práticas e aos discursos relacionados aos sentidos produzidos nas relações sócio-historicamente determinadas. No caso deste projeto 
esses sentidos são vinculados às violências que ocorrem e/ ou atravessam o espaço escolar.

A pesquisa-intervenção baseia-se, conforme Rocha (2006), nos princípios da Análise Institucional Socioanalítica - corrente desenvolvida na França durante as décadas de 1960/1970 que possui como teóricos expoentes René Lourau e Georges Lapassade -, e na Filosofia da Diferença, que possui como principais teóricos Gilles Deleuze e Félix Guattari.

Nessa abordagem de pesquisa, o conhecimento “(...) se constrói [...] entre o saber já elaborado e incorporado nos pressupostos do pesquisador e o fazer enquanto produção contínua que organiza a ação investigativa" (Rocha, 2006, p. 169); ou seja, ao mesmo tempo em que se produzem as práticas que constituem o social, vão se produzindo também os referenciais que lhes dão sentido. Dessa forma, as situações e os resultados implicados na pesquisa são sempre provisórios, e para compreendê-los é fundamental a contextualização dos fatores e a análise das forças que os produziram e dos efeitos das práticas.

Por meio da análise micropolítica do cotidiano, a pesquisa-intervenção possibilita a desnaturalização de discursos e práticas acerca das violências e permite abranger tanto o pesquisador como o pesquisado como participantes da produção do conhecimento.

\subsection{Procedimentos metodológicos}

As técnicas e instrumentos de produção das informações foram os seguintes: a) pesquisa documental referente aos resultados da pesquisa realizada anteriormente; b) observação participante de todo o processo de restituição dos resultados da pesquisa às escolas nela envolvidas, com registro no Diário de Pesquisa.

O processo de restituição de pesquisa constituiu-se de três etapas: a) Primeiramente estabeleceu-se o contato telefônico para agendar um encontro com o diretor, o coordenador ou orientador pedagógico; b) no encontro, efetuou-se a entrega do relatório com os resultados da pesquisa obtidos naquela escola e agendou-se uma data para a realização da atividade de restituição dos dados da primeira pesquisa e desenvolvimento da nova investigação (o público participante da presente pesquisa foi definido conforme a disponibilidade e interesse da escola); c) apresentação e discussão das informações, com estímulo ao debate e registro das atividades e informações produzidas. Todas as atividades foram registradas pelos pesquisadores por meio do Diário de Pesquisa.

A pesquisa abrangeu, desde o contato telefônico até a realização da atividade de restituição, doze escolas públicas estaduais ${ }^{3}$, as mesmas envolvidas na pesquisa exploratória que mapeou as práticas de violência em escolas, e 408 participantes: 221 alunos, 105 professores, 63 pais, oito coordenadores pedagógicos e onze diretores. A restituição

3 Foram abrangidas apenas doze escolas, não as treze envolvidas na pesquisa exploratória, porque a restituição de uma escola já tinha sido feita no ano de 2010. das informações foi realizada de quatro diferentes maneiras, conforme descrição a seguir.

1) Em quatro escolas foram realizados encontros com alunos e professores responsáveis pelas turmas naquele momento. A primeira escola contou com a participação de aproximadamente 50 alunos de duas turmas de sexta e sétima séries e quatro professores. Na segunda escola o encontro abrangeu aproximadamente 48 alunos de duas turmas do primeiro e segundo anos do Ensino Médio e quatro professores. Na terceira escola houve a participação de aproximadamente 48 alunos de duas turmas do Ensino Médio e dois professores. Na quarta escola realizou-se a atividade com 78 estudantes de duas turmas do segundo ano do Ensino Médio, além de três professores e uma coordenadora pedagógica. Nessas atividades, no primeiro momento foram apresentados os resultados da pesquisa realizada em 2009, com abertura para comentários e perguntas. Como não houve, já na devolução à primeira escola, muita participação em grande grupo, os/as pesquisadores passaram a solicitar aos estudantes, em todas as escolas, que se reunissem em pequenos grupos (de três a seis pessoas) para discutirem os resultados apresentados e escreverem seus apontamentos em folhas de papel, que seriam entregues aos/às pesquisadores/as. Para a sistematização dos dados da pesquisa, os pequenos grupos foram nominados por letras. As discussões tiveram como direcionamento as seguintes perguntas: a) $O$ que pensam dos resultados apresentados? b) Como percebem hoje a realidade da escola no que diz respeito às violências? Que novas informações vocês acrescentam: na relação entre estudantes; na relação entre professor/a e aluno/a; na relação entre aluno e escola? c) Como percebem hoje a realidade do entorno da escola? Que novas informações acrescentam? d) Que soluções apontam para as situações de violência presentes na escola? 2) Em uma escola foi realizado o encontro no final de uma assembleia de pais e professores, com a presença de 63 pais, 17 professores e a diretora da escola. 3) Em outra escola, o encontro foi realizado no início do conselho de classe e contou com a presença de 34 professores. 4) Em três escolas, os encontros foram realizados com diretores de escola, com entrega dos resultados e discussão das informações.

Ressaltamos que em três escolas realizou-se apenas a primeira visita ao diretor e orientador/orientadora pedagógi$\mathrm{co}$, com entrega do relatório de dados resultantes da pesquisa e tentativa de agendamento de data para discussão das informações com um público maior. A greve dos professores, com duração de 17 de abril a 09 de maio de 2012, foi uma dificuldade encontrada para a efetivação desses encontros.

\section{Resultados e discussão}

\subsection{Movimentos provocados pela pesquisa- intervenção}

A primeira questão sobre a qual o processo de restituição da pesquisa às escolas nos provoca a refletir é a 
própria pesquisa, ao modo como ela foi praticada e restituída aos participantes. A presente pesquisa foi feita a partir do lugar de psicólogos que trabalham com ensino e pesquisa em uma instituição de ensino superior. Machado (2003), que tem atuado por longo tempo no Serviço de Psicologia Escolar do Instituto de Psicologia da USP, tem sistematicamente problematizado a função estabelecida na relação entre a Psicologia e as escolas, perguntando-se: "[...] a serviço do quê trabalhamos nas escolas?" (p. 63). A autora lembra o fato de que a entrada do psicólogo nas instituições educativas aguça a expectativa de explicação do que acontece com os alunos, com base na ideia de que as características das queixas escolares são geralmente atributos individuais deles. Assim, precisávamos estar atentos para pôr em questão a máxima de que as práticas violentas são inerentes aos alunos, uma vez que podem ser explicadas como atributos individuais destes.

Esse alerta dado pela autora nos provocou a pensar sobre nossa entrada nos espaços onde a pesquisa ocorreu. Um fato importante que nos chamou a atenção foi a possibilidade, por nós percebida, de que o mapeamento de práticas violentas pudesse ser tomado pelos participantes da pesquisa como um equipamento operado por especialistas do comportamento humano para identificar os tipos de práticas violentas como se estas necessariamente estivessem presentes em todas as escolas participantes da pesquisa. Nosso propósito, diferentemente disso, era contribuir com a discussão dos resultados do mapeamento como possível dispositivo de intervenção do psicólogo na escola, a partir da mobilização dos diferentes atores, para reflexão sobre os atravessamentos presentes nas práticas violentas. Mais grave ainda - temíamos ainda que o mapeamento provocasse efeitos de generalização, ou seja, que a partir da pesquisa os participantes passassem a identificar os diversos tipos de práticas contidas no questionário do mapeamento como efetivamente existentes na escola na qual conviviam, inclusive passando denominar de violência práticas que não podem ser de fato caracterizadas como tal, isto é, mudando, a partir de verdades produzidas pela pesquisa (ou ao menos tomadas pelos participantes como tal), o estatuto de práticas que antes levavam o nome, por exemplo, de indisciplina, bagunça, "arte", baderna. Sobre este processo, Tondin (2008) opina que tais fatos, "[...] que sempre precisaram da mediação do processo educativo [...] colocam os adultos, hoje, em estado de impotência, de tal forma que é muito comum encontrarmos pais e professores que não sabem mais o que fazer com as crianças e adolescentes." (p. 215).

Tal generalização pode produzir também efeitos de disseminação, reificação, cristalização e naturalização das violências, o que só alimentaria processos de desqualificação daqueles espaços escolares, especialmente por serem escolas públicas estaduais, e de culpabilização dos que neles convivem, operando na lógica que Patto (1984, 1990) tão bem denunciou: dos mecanismos que transformam a desigualdade social - e no caso das violências não podemos deixar de analisá-las como relativas à estrutura capitalista - em questões individuais, eximindo o sistema social e político de implicação na produção das injustiças.

Assim nós nos indagávamos sobre os efeitos que as práticas de pesquisa e da Psicologia foram produzindo nas instituições educativas, sem deixar de reconhecer e afirmar também as potencialidades desta pesquisa, no sentido de que o ato de identificar práticas violentas presentes nas escolas poderia provocar processos de discussão e de busca de alternativas ao que antes era naturalizado. Durante o processo, percebemos que a pesquisa também promoveu movimentos transversais, no sentido de problematizar situações que estavam relativamente "acomodadas" no interior das escolas, como casos de assédio sexual e de "bullying" referidos pelos alunos, e das constantes agressões verbais aos professores.

\subsection{Processo de restituição da pesquisa: atores tecem conhecimentos e sentidos}

O processo de restituição da pesquisa aos participantes, mais do que para discutir as informações produzidas, foi uma oportunidade para alunos, professores e pais falarem sobre as relações entre eles, e principalmente para dizer como gostariam que estas relações viessem a desenvolver-se.

Nas produções escritas resultantes das discussões em pequenos grupos, os estudantes citaram situações que aconteciam em suas escolas.

Na relação entre estudantes, nós achamos que os alunos não se respeitavam como deveriam: havia brigas e agressões verbais com palavras muito baixas (Grupo B).

A violência entre os estudantes é muito comum em nossa escola (principalmente com aqueles que possuem uma estatura mais baixa), atiram pedaços de papel com borrachinhas de amarrar dinheiro, o bullying contra a opção sexual de alguns alunos, a aparência de alguns alunos e sua classe social. (Grupo A).

Entre os estudantes: está cada vez mais difícil o relacionamento. Às vezes um motivo que começa do nada pode virar em um ato de vandalismo. (Grupo D).

Apesar de um grupo de estudantes afirmar: "Não há muitas agressões e violências na escola", citou uma situação que ocorreu entre dois estudantes: "Eles quase se mataram dentro da sala, de faca, soqueira e canetas". Outras situações com presença de violência na relação entre estudantes também foram destacadas por familiares e professores. Uma mãe referiu que seu filho "reclamava muito que puxavam suas calças" e uma professora relatou que uma aluna ao ser chamada à atenção, foi até o banheiro, deu um soco no espelho, quebrando-o e ferindo-se.

Quanto às violências na relação entre aluno e professor, os estudantes evidenciaram as agressões verbais e fal- 
ta de respeito por parte de professores, afirmando que eles impunham respeito pela altura da voz, deboche e exercício de autoritarismo:

A violência é verbal, muitos professores perseguem'os alunos (dão notas baixas, criam intrigas e brigas com estudantes), mas os alunos às vezes também merecem. (Grupo E).

Na relação entre professor e aluno o que acontece muitas vezes é que os professores sentem-se superiores aos alunos e acabam fazendo um tipo de "ditadura", onde o professor manda e o aluno simplesmente obedece, não aceitam críticas e correções. (Grupo F).

Por outro lado, estudantes, professores e diretores também destacaram a falta de respeito do aluno para com o professor.

Os alunos (alguns) não respeitam mais os professores, e os tratam como se fossem insignificantes, sem nenhum respeito. (Grupo G).

Na relação entre professor e aluno: há muitas discriminações, exemplo aqui na escola, há um professor com deficiência visual, e na aula dele, quase ninguém o respeita, os alunos fazem o que querem. (Grupo $\mathrm{H}$ ).

O Grupo I ressaltou uma interligação entre as agressões entre professores, estudantes e normas da escola: "Às vezes os professores erguem o tom de voz e os alunos revidam e ocorre uma agressão verbal. E os alunos podem ser expulsos. E assim ameaçam os professores, e vice-versa".

Foram também citados exemplos de danificação de objetos e da estrutura física da escola, destruição de horta, pichação de muros e paredes e roubo de materiais por parte de estudantes. Também foram mencionadas violências nas proximidades da escola, como casos de agressão física, tráfico e uso de drogas, agressão verbal, furtos e a presença de gangues. Por outro lado, alguns alegaram não saber da ocorrência de violência nas proximidades.

Pudemos perceber em todas as situações relatadas que os estudantes, pais e professores sentiam-se afetados de alguma forma pelas violências presentes, o que abre espaço para a discussão sobre esse tema e a possibilidade de construção de outros modos de relação. O tema das práticas violentas na escola é, atualmente, um dos que mais mobilizam os participantes do processo educativo, não apenas pela frequência das ocorrências, referida em geral como cada vez maior, mas pelos efeitos que elas produzem no cotidiano de alunos, professores e pais; afinal, não há como negar que os efeitos destas são muito prejudiciais ao desenvolvimento e aprendizagem dos alunos, ao modo como os professores encaram sua profissão e como se dão as relações entre famílias e escolas.

Na realidade, este tema não é mobilizador por si só, mas diz respeito também a uma série de questões que precisam ser repensadas na escola, ao jogo de forças que se dá no interior dela, o qual determina um cotidiano cada vez mais mecanizado, em que professores e alunos não veem mais sentido para o trabalho escolar, trabalho que frequentemente é organizado de modo homogêneo. A desconsideração da diversidade dos sujeitos e das especificidades locais das comunidades acaba por desumanizar as relações e serializar as subjetividades.

No tocante às soluções apontadas pelos diferentes atores para as situações de violência mapeadas por esta pesquisa, a estratégia predominantemente apontada para diminuir as violências, tanto pelos estudantes como por familiares, professores e diretores, foi a presença de policiais ou guardas na escola e em torno dela. A solução indicada acompanha a lógica de separação entre o mundo de dentro e o de fora da escola, na qual a polícia representa a certeza dessa separação; no entanto consideramos que o tema das violências nas escolas é um exemplo de como a educação escolar não pode mais se colocar isenta ou à parte do mundo social, pois trata-se de uma problemática que, embora aparentemente seja produzida na família e na sociedade em geral e que, no pensamento de muitos profissionais e pais, deveria permanecer e ser resolvida no âmbito destas instâncias, na realidade rompe os muros escolares para se fazer presente no interior deste espaço, atualizando-se de acordo com as especificidades de cada escola.

Rocha (2000) afirma que os saberes e práticas escolares que configuram a educação estabelecem uma série de oposições, como o certo e o errado, o bom e o ruim, etc., e acrescentamos o dentro e o fora da escola. "Em meio à lógica binária, a diferença é o excluído [...]. A lógica dominante ganha espaço, constituindo-se enquanto síntese das estabilidades e exclusão das variâncias, das singularidades." (p. 191). Nessa lógica, violência, drogas, DSTs/AIDS, gravidez na adolescência e outras questões são temas que deveriam permanecer fora da escola, devendo haver dentro dela apenas o ensino de conteúdos, a ordem, a disciplina, corpos e mentes ávidos de absorver o que os livros e os professores transmitem.

Observa-se, embora cada vez menos, que professores e pais desejam que a escola esteja alheia a estes assuntos, que ela "feche as portas" para os problemas sociais (numa ilusão de que isso possa ser possível), pois eles fariam parte do que não faz parte do trabalho da escola, mas de algo ou alguém que fica fora da escola. Essa dicotomia dentro/fora da escola também apareceu durante a pesquisa, num debate entre professores em uma reunião de que participamos. Uma professora argumentou que a escola, em uma situação de uso de drogas fora da escola por um aluno, devia chamar os pais para tentar resolver o fato. Outro professor contestou, afirmando que o que acontece fora da escola é algo do interesse do aluno, não cabendo ação da escola. Duas professoras ratificaram a posição, alegando que se a escola não possui provas sobre os fatos (uso de drogas na escola) não deve falar aos pais, pois eles não acreditariam.

A dicotomia dentro/fora da escola, constatada pela presente pesquisa, tem sido superada por uma análise que 
percebe criticamente que a escola, tal como se instituiu, tornou-se um espaço e um tempo distinto e destinado às aprendizagens formais que acabou por estabelecer uma ruptura com a experiência dos alunos e com a vida das comunidades. "A separação da realidade social produziu um efeito de fechamento da escola sobre si mesma [...]. Subestimar a experiência dos aprendentes tem-se traduzido em um déficit de sentido do trabalho escolar, marcando negativamente a relação com o saber." (Canário, 2006, p. 13). Não é à toa que alunos e professores têm estado cada vez mais desencantados com a escola, afinal, não veem sentido em processos formais, burocratizados e mecanizados que ali se consolidaram e se perpetuam.

Outro aspecto a ser considerado que surgiu em vários momentos de realização das discussões pelos participantes da pesquisa é principalmente a culpabilização de alunos e suas famílias; dos professores em frequência relativamente menor e, em escala menor ainda, instâncias públicas (governo, polícia) pelas práticas violentas que ocorrem no ambiente e no entorno escolar. Percebemos que o mecanismo de culpabilização dos indivíduos é atualizado e revigorado cotidianamente nos ambientes escolares, e quando algo se dá em desacordo com o regulado pela escola ou pelo meio social, como é o caso das violências, esse mecanismo é imediatamente acionado.

Machado (2007) afirma que o mecanismo de produção de culpados impede perceber que o que está sendo vivido é efeito de um campo de forças múltiplas, ou seja, que todos os envolvidos, sujeitos e instituições, participam desta produção e, nesta mesma linha de raciocínio, participam também da constituição das práticas violentas. Isto evidencia a dificuldade de cada um se reconhecer como implicado nestas práticas e facilita o acionamento do mecanismo de culpabilização, afinal, "A realidade psíquica e a realidade material de produção social passam a ser vistas como distintas." (Machado, 2007, p. 122).

A sugestão de uma diretora de que, em contraposição a esse mecanismo, haja articulação e troca de informações entre a escola e a população da região onde está situada pode se constituir como uma interessante estratégia de enfrentamento de situações de violências. Nesse caso, mais do que atribuição de responsabilidades, esboça-se um esforço conjunto e integrado dos vários atores para a identificação de práticas violentas e criação de outras possibilidades de ação e relação.

A abordagem institucionalista, por nós utilizada na análise das informações desta pesquisa, permite perceber a pouca importância que os participantes deram à participação ou ausência das políticas públicas na produção e na solução das práticas violentas nas escolas, o que parece quase uma isenção delas quanto à constituição do fenômeno e uma desresponsabilização do ente público no cuidado e atenção aos problemas sociais. De nossa parte, consideramos, em concordância com Bonamigo e cols. (2011, p. 800), que as violências devem ser concebidas "como um tema transversal do conjunto de políticas públicas, a segurança pública como um direito fundamental, e os municípios como cogestores da área de segurança e na prevenção de violências."

\subsection{Transformando fragilidades em potências}

Mesmo sendo a escola um espaço de exercício de poderes disciplinares, é possível pensá-la como instituição em movimento, por isso é preciso identificar as diferenças que se produzem nos processos cotidianos, tecendo linhas de fuga (Rocha, 2000, Machado, 2003, 2007). Compreendemos que a escola precisa ser pensada em rede com/na sociedade, pois, a não ser assim, a tendência é culpabilizarmos seus atores ou a própria instituição - tendência, aliás, que tem sido utilizada como se atendesse a uma perspectiva crítica em Psicologia Escolar, porém, mantém a lógica de culpabilização e psicopatologização dos processos escolares, focando a própria organização escolar como a responsável pelos "prejuízos" à saúde mental dos seus participantes.

Para tal, é preciso um reposicionamento dos experts na sua relação com as comunidades escolares, na direção apontada por Baremblitt (1994, p. 22): "[...] recuperar, revalorizar o saber espontâneo que elas têm sobre seus problemas". O mesmo autor continua: "Uma vez que o expert, integrado à comunidade, demonstra a capacidade de contribuir, em pé de igualdade, para este trabalho de reformulação, pode-se delegar a eles algumas área do saber, com menos perigo de que ele o transforme em poder [...]". (Baremblitt, 1994, p. 22).

Foi a partir desta perspectiva que nós, pesquisadores, inserimo-nos nas escolas neste processo de restituição aos coletivos participantes do mapeamento realizado na pesquisa anterior e produção da nova pesquisa e é, também a partir desta perspectiva que acreditamos que o trabalho referente às práticas violentas nas escolas possa ser feito, pois envolve participação, criticidade e protagonismo de todos os envolvidos na questão.

Para tal, as práticas violentas precisam ser tomadas como potência, ou seja, como conflitos que expressam forças que estão em jogo no espaço institucional e questionam os modos hegemônicos da organização escolar, ritualizados e enrigecidos, e o funcionamento social, individualista e competitivo. Isto significa que nossa proposta é sair do território do indivíduo para pensar este fenômeno como expressão social, política, econômica, cultural. Nessa direção, Rocha (2000) explica: "[...] nossa perspectiva está na abertura de espaços que permitam à comunidade escolar, [...] discutir suas implicações com a construção do cotidiano educacional, envolvendo [...] diversidade de posições ante o processo, assim como as insatisfações, demandas e alternativas". (p. 186).

A questão é como viabilizar a abertura destes espaços diante da realidade das escolas públicas estaduais catarinenses, as quais, sob a égide de regulamentação nacional, estão submetidas a uma gestão estadual que pouco se esforça para pensar alternativas no plano macro e nem mesmo permite às escolas que pensem saídas no 
plano micropolítico. Como viabilizar esse processo se é preciso cumprir 200 dias de "efetivo trabalho com o aluno"? Tal determinação diminuiu em muito os encontros que existiam entre os professores, nos quais eles podiam planejar, estudar, trocar, avaliar, conversar, conflitar, divergir, convergir, conviver, enfim, dialogar. Machado (2007, p. 124) nos alerta: "Se esses espaços e tempos são reduzidos ou dificultados na instituição, se as políticas inventadas assujeitam os atores da instituição, então a potência de troca e a criação de saberes ficam reduzidas."

Buscamos também as palavras de Machado (2007) para enfatizarmos a importância destes encontros na promoção de um deslocamento do modo como normalmente a discussão tem sido conduzida:

Para isso é necessário sair do território individualizado e naturalizado e buscar a expansão do campo problemático, ir para o território do múltiplo. O modo de fazer isso está na produção coletiva, na criação de espaços e tempos nos quais as professoras possam compartilhar saberes, multiplicar hipóteses, desequilibrar as crenças que sustentam os fazeres. Portanto, precisamos de uma atmosfera, um clima de conversa e discussão no qual essas produções possam se dar. (p. 124).

Com professores sobrecarregados de trabalho, efetivar estes momentos muitas vezes tem sido quase sinônimo de penalização destes, dada a imposição de uma sobrecarga de trabalho, o que acaba por desmobilizar os coletivos. Em nossa avaliação, isso não é feito sem uma clara intenção política do Estado de fragilizar os vínculos de trabalho em cada unidade escolar, que é vista como célula micropolítica de uma organização política maior, como, por exemplo, a sindical e a de articulação com a comunidade, em que "[...] grupos são espaços táticos de produção de subjetividade e, portanto, abrem condições para que possam ocorrer mudanças." (Machado, 2007, p. 143). Assim, com a inviabilização da existência de coletivos, reforça-se o que Rocha (2000, p. 194) denomina de "éticas verticais do assistencialismo à brasileira", as quais "[...] trazem como correlato às amarras dos profissionais da Educação: a fragilização, a impotência, o desinvestimento na formação e na participação ativa e a exploração."

Por outro lado, com base na perspectiva institucionalista, podemos afirmar que o sistema escolar não existe sem resistência ao instituído, sem manifestação de contrários e de conflitos que fraturam a dureza organizacional estabelecida. Diante da instituição de processos totalizantes que buscam uniformizar as práticas educativas nas escolas, pode-se empreender uma luta pela "polissemia da expressão" dos atores que nelas convivem, no plano da micropolítica, atuando nas "brechas" em busca de outros "tempos/espaços", como nos aponta Rocha (2000, p. 194). A autora sugere:

Para enfrentarmos a sensação de impotência de criar, o tédio institucional produzido nas instituições atuais, um outro plano do real precisa de escuta: o plano das turbulências, das intensidades, nível no qual se dão as afecções [...], facultando o envolvimento, as implicações e a ação. (Rocha, 2000, p. 194).

Diante de uma realidade institucional de encontros tão despotencializadores, até que ponto as violências não são estratégias de romper com o tédio e a monotonia escolar? Esta é uma questão nos instiga e leva a pensar que "[...] o tédio pode ser compreendido como enfraquecimento dos territórios tradicionais existentes que perdem credibilidade e consistência, desabamento de antigas territorialidades existenciais." (Rocha, 2000, p. 198). Para entender o tédio é preciso adentrar em outro plano institucional: o do invisível, do cotidiano, das lutas micro, ou seja, escapar da tendência de pensar a escola apenas pela via da macropolítica (o plano molar) pela qual são vistas as escolas, tendo-se um contorno geral da organização escolar, e não de cada escola em sua singularidade. "Essa priorização traz como conseqüência o bloqueio à criação de condições para a perspectiva de um real provisório, processual, não totalizado, para a produção de micropolíticas da invenção que evidenciam um cotidiano em análise produzido nas práticas coletivas". (Rocha, 2000, p. 197).

Neste processo, podemos buscar, de modo implicado, as responsabilidades dos envolvidos no processo educativo, para pensarmos as ações de cada um no que tange às violências que são produzidas na trama das relações sociais. "Isso exige que criemos dispositivos que permitam fazer novas conexões, valorizar produções desconsideradas, agir de maneira que novas possibilidades contaminem esse campo de relações." (Machado, 2007, p. 123). Para isso, precisamos sair do território dos especialismos, afinal: "Onde ninguém sabe e todos sabem surge uma brecha na qual o desejo pode aparecer." (Rocha, 2000, p. 198).

\section{Considerações finais}

A pesquisa-intervenção mostrou ser uma importante ferramenta teórico-metodológica para a realização do processo de restituição da pesquisa que mapeou as práticas violentas na escola. Permitiu-nos tornar o processo de restituição de conhecimento um laboratório de experimentação coletiva, constituindo-o em uma nova pesquisa que possibilitou que outras informações emergissem nesse processo. A sua maior riqueza foi colocar em análise o cotidiano da pesquisa, o papel de pesquisador, as relações que foi possível estabelecer no processo de restituição/produção de conhecimento.

O mapeamento de violências feito anteriormente serviu como aquecimento para a discussão e, principalmente, trouxe para o momento da discussão as vozes dos atores da escola (profissionais, alunos e familiares), já que não foi possível um espaço e momento em que todos estivessem presentes ao mesmo tempo. Neste sentido, pode ser utilizado como dispositivo de intervenção do psicólogo na escola, 
para mobilizar os diferentes atores e contribuir para a reflexão sobre questões que atravessam a comunidade escolar.

A questão das violências tem permitido que entrem nas escolas outros profissionais e saberes, como a Psicologia Escolar e o psicólogo. Isso é potencialmente interessante, mas é preciso tomar cuidado, porque pode ser uma porta de entrada para explicações e medidas que mais podem atravessar o cotidiano escolar com lógicas totalmente alheias ao processo educativo, como se deu, por exemplo, nos anos 1980 e 1990, período de implementação das ideias neoliberais globalizantes em nosso país, como tentativa de transferir medidas tomadas da ciência da administração para serem praticadas na escola, a partir de um diagnóstico de que a educação era "ineficiente", "ineficaz" e de "baixa qualidade" e de que a causa deste quadro seria o mau gerenciamento dos processos escolares, portanto, de que as ideias e estratégias da qualidade total, de base japonesa, seriam a solução para os problemas da educação "subdesenvolvida" deste país também "subdesenvolvido".

De nossa parte, achamos que é necessária, sim, a interlocução das ciências da educação com domínios científicos e profissionais diversos, porém esta relação deve ser de autonomia, de forma que os campos se afetem mutuamente. Não se trata, assim, de a Psicologia ser aplicada à Educação, mas de interatuar e dialogar com ela, de modo que os campos possam ser transversalizados pelos conceitos e reflexões de ambos.

O tema das violências permite pensar também a imperiosa necessidade de superar as atuais formas escolares de educar, as quais demonstram um estado cada vez mais agudo de esvaziamento e esgotamento, em uma sociedade pós-industrial de base tecnológica. Isso requer pensar a educação como processo que deve ser feito em rede, com base territorial, trazendo o mundo social para dentro da escola e levando o mundo escolar para fora desta instituição.

\section{Referências}

Baremblitt, G. F (1994). Análise institucional e outras correntes: teoria e prática. 2. ed. Rio de Janeiro: Rosa dos Tempos.

Bonamigo, I. S., Bruxel, K. , Solivo, E. , Tremea, F. F. , Dameda, C., \& Martini, C. (2011). Violências, direitos humanos e segurança pública em debate. Psicologia: Ciência e Profissão, 31, 800-813.

Bonamigo, I. S., Tondin, C. F., Bortolossi, F., Seraglio, K., Schott, D. F., \& Martinelli, M. (2012). Mapeamento de práticas violentas como dispositivo de intervenção da psicologia na escola. Psicologia Argumento, 30(70), 525-535.
Canário, R. (2006). A escola tem futuro? Das promessas às incertezas. Porto Alegre: Artmed.

Charlot, B. (2002). A violência na escola: como os sociólogos franceses abordam essa questão. Sociologias, 4 (8), 432-443.

Guattari, F. (1992). Caosmose: um novo paradigma estético. São Paulo: Ed. 34.

Lourau, R. (1993). Análise Institucional e Práticas de Pesquisa. Rio de Janeiro: UERJ.

Machado, A. M. (2003). Os psicólogos trabalhando com a escola: intervenção a serviço do quê? Em Meira, M.E.M, \& Antunes, M.A.M. Psicologia escolar: práticas críticas (pp. 63-85). São Paulo: Casa do Psicólogo.

Machado, A. M. (2007). Plantão institucional: um dispositivo criador. Em Machado, A. M., Fernandes, A.M.D., \& Rocha, M.L. (Orgs.). Novos possíveis no encontro da psicologia com a educação (pp. 117-143). São Paulo: Casa do Psicólogo.

Patto, M. H. S. (1984). Psicologia e ideologia: uma introdução crítica à psicologia escolar. São Paulo: T. A. Queiroz.

Patto, M. H. S (1990). A produção do fracasso escolar: histórias de submissão e rebeldia. São Paulo: T. A. Queiroz.

Rocha, M. L. (2000). Educação em tempos de tédio: um desafio à micropolítica. Em Tanamachi, E. R., Proença, M., \& Rocha, M.L. Psicologia e educação: desafios teórico-práticos (pp. 185- 207). São Paulo: Casa do Psicólogo.

Rocha, M. L., \& Aguiar, K. F (2003). Pesquisa-Intervenção e a produção de novas análises. Psicologia Ciência e Profissão, 23 (4), 1-16.

Rocha, M. L. (2006). Psicologia e as práticas institucionais: a pesquisa-intervenção em movimento. Psico, 37 (2), 169-174.

Tondin, C. F. (2008). Violências nas escolas e territórios educativos. Em Bonamigo, I. S., Tondin, C. F., \& Bruxel, K. As práticas da Psicologia Social com(o) movimentos de resistência e criação (pp. 207-21). Porto Alegre: Abrapso Sul.

Varela, J., \& Alvarez-Uria, F. A (1992). Maquinaria escolar. Teoria e Educação, 6, 68-96.
Recebido em: 26/04/2013

Reformulado em: 16/12/2013

Aprovado em: 31/12/2013 


\section{Sobre as autoras}

Irme Salete Bonamigo (bonamigo@unochapeco.edu.br) Universidade Comunitária da Região de Chapecó (Unochapecó). Doutora em Psicologia Social pela Universidade do Estado do Rio de Janeiro (UERJ).

Celso Francisco Tondin (tondin@unochapeco.edu.br) Universidade Comunitária da Região de Chapecó (Unochapecó). Doutor em Psicologia pela Pontifícia Universidade Católica do Rio Grande do Sul (PUCRS).

Ana Paula Risson (anarisson@unochapeco.edu.br) Universidade Comunitária da Região de Chapecó (Unochapecó). Psicóloga graduada pelo Curso de Psicologia da Unochapecó.

Alana Lazaretti Solvalagem (alana.lazaretti@gmail.com)

Universidade Comunitária da Região de Chapecó (Unochapecó). Estudante do Curso de Psicologia da Unochapecó.

A pesquisa foi aprovada pelo comitê de Ética em Pesquisa da Unochapecó (Parecer Registro $n^{\circ}$ 67/10) e teve apoio financeiro do Fundo de Apoio à Pesquisa da Unochapecó (FAPE) e bolsa de iniciação científica concedida pelo Estado de Santa Catarina, regulamentada pelo Artigo 170 da Constituição Estadual. 